\title{
Wet chemical deposition of ATO and ITO coatings using crystalline nanoparticles redispersable in solutions
}

\author{
C. Goebbert ${ }^{\mathrm{a}}$, R. Nonninger ${ }^{\mathrm{b}}$, M.A. Aegerter ${ }^{\mathrm{a}, *}$, H. Schmidt ${ }^{\mathrm{b}}$ \\ a INM-Institut für Neue Materialien, Department of Coating Technology, Im Stadtwald, Gebäude 43, D-66123 Saarbrücken, Germany \\ ${ }^{\mathrm{b}}$ INM-Institut für Neue Materialien, Department of Chemistry and Technology of non-metallic inorganic materials, Im Stadtwald, Gebäude 43, D-66123 \\ Saarbrücken, Germany
}

\begin{abstract}
The deposition of $\mathrm{SnO}_{2}: \mathrm{Sb}$ (ATO) and $\mathrm{In}_{2} \mathrm{O}_{3}: \mathrm{Sn}$ (ITO) transparent conducting coatings on glass substrate has been demonstrated by many techniques such as CVD, sputtering, vacuum deposition and sol-gel process. This paper presents an alternative process for the deposition of such coatings at room temperature by spin, dip and spray coating techniques using solutions prepared with crystalline nanoparticles fully redispersed in water (for ATO, ITO) or alcohol (for ITO) with solid contents up to 10-15 Vol.\%, respectively. The deposited green coatings have been sintered at temperature as high as $900^{\circ} \mathrm{C}$. $\operatorname{In}_{2} \mathrm{O}_{3}$ :Sn coatings have a resistivity of $1.5 \times 10^{-2} \Omega \mathrm{cm}$ as sintered and $3.4 \times 10^{-3} \Omega \mathrm{cm}$ after annealing in nitrogen atmosphere. The resistivity of ATO single coatings shows a minimum $\rho=1.7 \times 10^{-2} \Omega \mathrm{cm}$ after annealing at $550^{\circ} \mathrm{C} . \mathrm{SnO}_{2}: \mathrm{Sb}$ coatings present long term stability but the resistivity of annealed ITO coatings steadily increases with time to a value three times higher. All coatings have a high optical quality with transmission in the visible range larger than 90\%. C) 1999 Elsevier Science S.A. All rights reserved.
\end{abstract}

Keywords: Indium tin oxide; Antimony; Tin oxide; Conductivity; Nanoparticles

\section{Introduction}

Transparent conducting oxides (TCO) deposited on glass are important materials in the field of optoelectronic devices such as solar cells, electroluminescence and liquid crystal displays [1]. The n-type semiconductors such as indium tin oxide $\mathrm{In}_{2} \mathrm{O}_{3}$ :Sn (ITO) [2], fluorine or antimony doped tin dioxide (FTO, ATO), aluminium or gallium doped zinc oxide (AZO, GZO) are widely used as transparent electrodes in these applications. Practically all known coating processes have been used for their preparation [1-3].

The sol-gel route leads to coatings presenting a relatively high resistivity $\rho$. For $\mathrm{SnO}_{2}: \mathrm{Sb}$ coatings the published values vary from $3 \times 10^{-3} \Omega \mathrm{cm}[4]$ and $2.1 \times 10^{-2} \Omega \mathrm{cm} \mathrm{[5]} \mathrm{but}$ the resistivity of $\operatorname{In}_{2} \mathrm{O}_{3}: \mathrm{Sn}$ is as small as $\rho=8 \times 10^{-4} \Omega \mathrm{cm}$ [2]. $\mathrm{SnO}_{2}: \mathrm{Sb}$ coatings have a higher mechanical and thermal stability than ITO coatings. The reasons for the low conductivity of sol-gel $\mathrm{SnO}_{2}: \mathrm{Sb}$ and $\mathrm{In}_{2} \mathrm{O}_{3}: \mathrm{Sn}$ films is due to their high porosity (low density) [6] even after sintering at high temperature. Structures with large and closely packed crystallites as obtained by spray pyrolysis, sputtering and CVD

\footnotetext{
* Corresponding author. Tel.: + 49-681-9300 317; fax: + 49-6819300-249.

E-mail address: aegerter@inm-gmbh.de (M.A. Aegerter)
}

processes exhibit higher electron mobility and carrier density and consequently lower electrical resistivity.

A new concept based on the use of solutions containing already densified crystalline $\mathrm{SnO}_{2}: \mathrm{Sb}$ or $\operatorname{In}_{2} \mathrm{O}_{3}: \mathrm{Sn}$ nanoparticles have been developed for the preparation of coatings (Fig. 1). This work outlines the preparation of crystalline ATO and ITO nanoparticles fully redispersable in a solvent, the sol and particle characterisation and the optimisation of the dopant content with respect to the electrical resistivity. The paper also describes various coating procedures and discusses the influence of the densification temperature and sintering time on the optical and electrical properties of such coatings.

\section{Experimental}

$\mathrm{SnO}_{2}: \mathrm{Sb}$ and $\mathrm{In}_{2} \mathrm{O}_{3}: \mathrm{Sn}$ powders were prepared by a controlled growth technique [7-9]. A solution of tin (IV) chloride or indium (III) chloride in ethanol containing 0.1$10 \mathrm{~mol} \%$ of $\mathrm{SbCl}_{3}$ or $\mathrm{SnCl}_{4}$, respectively was added dropwise to an aqueous ammonia solution containing $10 \mathrm{wt} . \%$ (with respect to the oxide) of a surface modifying agent, $\beta$ alanine. The ATO suspensions were treated at $150^{\circ} \mathrm{C}$ and 10 bar for $3 \mathrm{~h}$ under hydrothermal conditions, the ITO suspensions at $80^{\circ} \mathrm{C}$ for $24 \mathrm{~h}$ under atmospheric pressure. The 


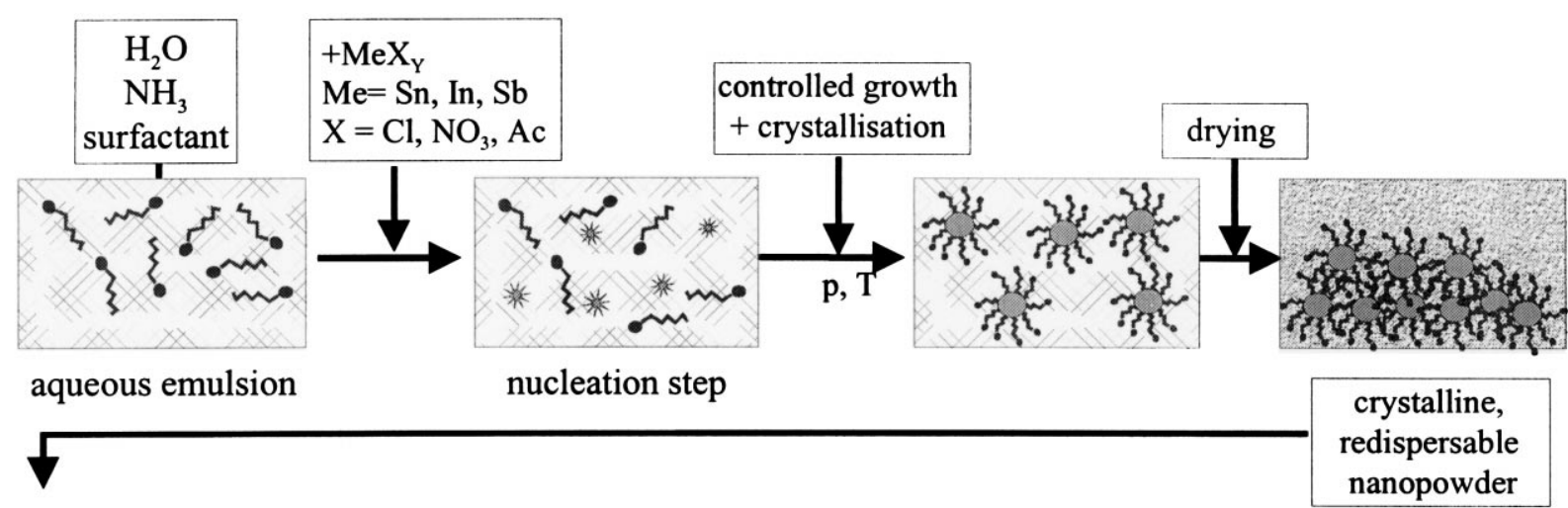

Processing A

heat treatment

Processing B

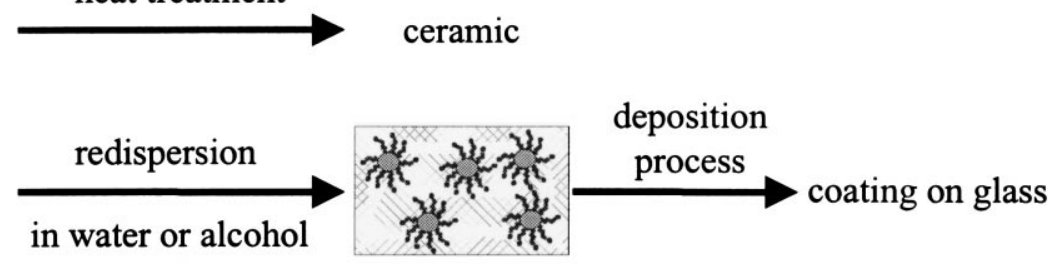

Fig. 1. Concept for the preparation and the use of crystalline nanoparticles using the controlled growth reaction.

resulting powders were isolated by centrifugation, washed with water several times and then dried at $60^{\circ} \mathrm{C}$. The dried ITO powder was annealed at $300^{\circ} \mathrm{C}$ in a reducing atmosphere.

The powders were characterised by high resolution transmission electron microscopy (HRTEM-CM200 FEG, Philips) and X-ray diffraction (D500, Siemens)). Their crystallite size was calculated using the Siemens software.

Colloidal suspensions of ATO were prepared by redispersing the dried powder in water at $\mathrm{pH} \geq 9$ using tetramethylammoniahydroxide as dispersion agent. The suspensions were then treated with ultrasonic irradiation for $2 \mathrm{~min}$ and then stirred during 1 day. They are clear with a yellowish orange colour.

Dried ITO powder was mechanically redispersed in ethyleneglycol with a carbon acid as dispersion agent and the solution was then added to ethanol or water.

Both suspensions showed a blue colour. The solutions are stable with solid contents up to $10-15 \mathrm{Vol} . \%$ and do not present precipitation during several months. They were characterised by measurement of the zeta potential (Zetasizer, Malvern) and the hydrodynamic particle size (ultrafine particle analyser, UPA).

$\mathrm{SnO}_{2}: \mathrm{Sb}$ coatings were prepared by spin coating process on clean $5 \times 5 \mathrm{~cm}^{2}$ borofloat substrates using $500 \mu$ l of the dispersion and a final speed of $2000 \mathrm{rev} . / \mathrm{min}$ for $15 \mathrm{~s}$. The ITO films were prepared by dipping $7.5 \times 2.5 \mathrm{~cm}^{2}$ clean silica substrates into the dispersion and withdrawing them at a constant speed of $3 \mathrm{~mm} / \mathrm{s}$. The thermal densification of the films was carried out in a furnace in air up to $900^{\circ} \mathrm{C}$. The ITO coatings were annealed afterwards in a $\mathrm{N}_{2}$ atmosphere at a temperature of $300^{\circ} \mathrm{C}$.

The following characteristics of the coatings were measured: sheet resistance (4 point-technique), film thickness (P10 surface profiler, Tencor), roughness (scanning force microscopy, SFM), porosity (ASAP2400, Micromeritics, surface acoustic wave (SAW), self made instrument) and optical reflection and transmission (Cary 5E, Varian).

\section{Results and discussion}

\subsection{Powder and sol characterisation}

The structure of dried $\mathrm{SnO}_{2}, \mathrm{SnO}_{2}: \mathrm{Sb}$ and $\mathrm{In}_{2} \mathrm{O}_{3}: \mathrm{Sn}$

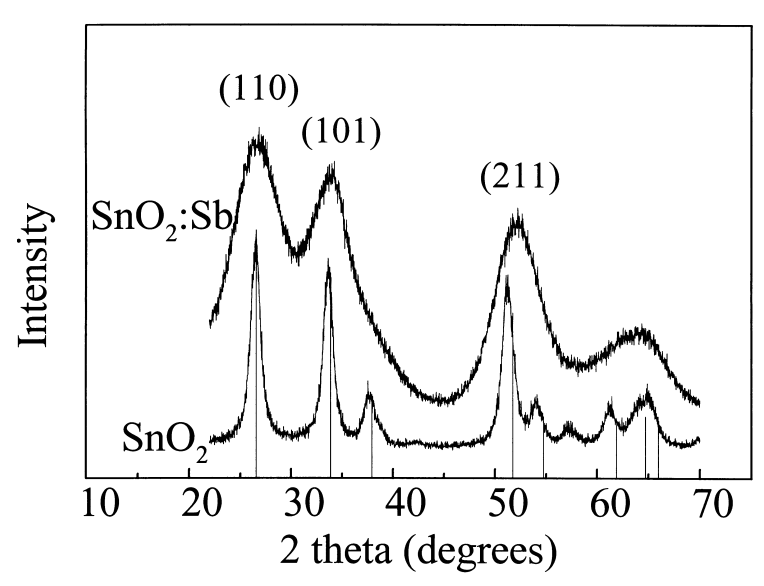

Fig. 2. (A) X-ray diffraction of dried nanoscaled, crystalline $\mathrm{SnO}_{2}$ powder prepared by a controlled growth reaction at $150^{\circ} \mathrm{C}$ and 10 bar for $3 \mathrm{~h}$. The vertical lines correspond to the data of the JCPDS database, Table 41-1445 (cassiterite structure). (B) X-ray diffraction of nanoscaled, crystalline $\mathrm{SnO}_{2}: \mathrm{Sb}$ powder prepared by a controlled growth reaction at $150^{\circ} \mathrm{C}$ and 10 bar for $3 \mathrm{~h}$. 


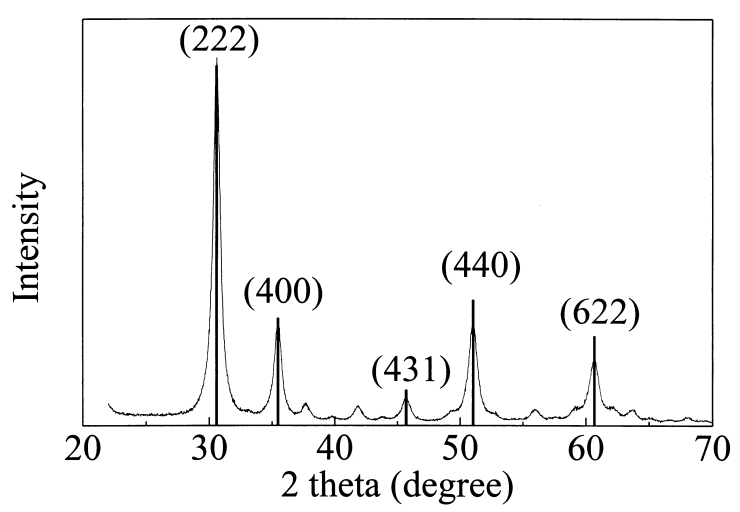

Fig. 3. X-ray diffraction of dried and annealed nanoscaled, crystalline $\mathrm{In}_{2} \mathrm{O}_{3}: \mathrm{Sn}$ powder prepared by a controlled growth reaction at atmospheric pressure. The vertical lines correspond to the data of the JCPDS database, Table 06-416 (cubic indiumoxide structure).

powders are shown in Figs. 2 and 3, respectively. The particles are already crystalline and have a cassiterite structure for $\mathrm{SnO}_{2}, \mathrm{SnO}_{2}: \mathrm{Sb}$ and a cubic $\mathrm{In}_{2} \mathrm{O}_{3}$ phase for the ITO powder. The TO, ATO and ITO crystallites are not oriented. The crystallite size, calculated from the (110) peak, is $7 \mathrm{~nm}$ for $\mathrm{SnO}_{2}$ and $3 \mathrm{~nm}$ for $\mathrm{SnO}_{2}: \mathrm{Sb}(5 \mathrm{~mol} \% \mathrm{Sb})$. A systematic decrease of the crystallite size was observed with increasing antimony content. The crystallite size of $\mathrm{In}_{2} \mathrm{O}_{3}: \mathrm{Sn}$ is $15 \mathrm{~nm}$ using the (222) peak.

For the preparation of the coatings the nanoscaled crystalline particles were redispersed in water (ATO, ITO) or in ethanol (ITO). The stability of the dispersion was determined by measuring the $\xi$ potential and is strongly dependant on the $\mathrm{pH}$ of the solvent (Fig. 4). The isoelectric point of the surface modified ATO powder lies at $\mathrm{pH}_{\text {iep }}=3.7$ and the suspension is stable for $\mathrm{pH}>8$. The isoelectric point of the ITO suspension is $\mathrm{pH}_{\text {iep }}=8.5$ and the suspension is stable for $\mathrm{pH}<6$.

A typical hydrodynamic size distribution of the particles is shown in Fig. 5. The average values are identical to the values of the crystallite size determined from the X-ray measurement. These results indicate that the particles are

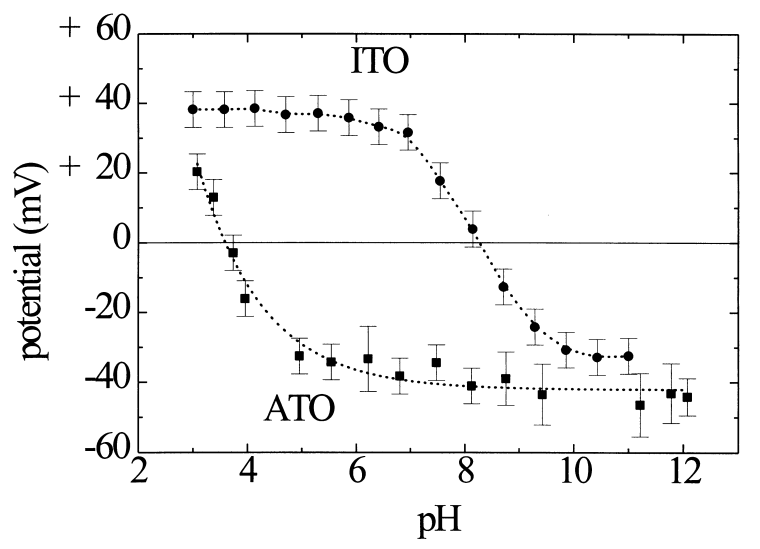

Fig. 4. $\xi$ potential of ATO and ITO suspensions versus $\mathrm{pH}$.

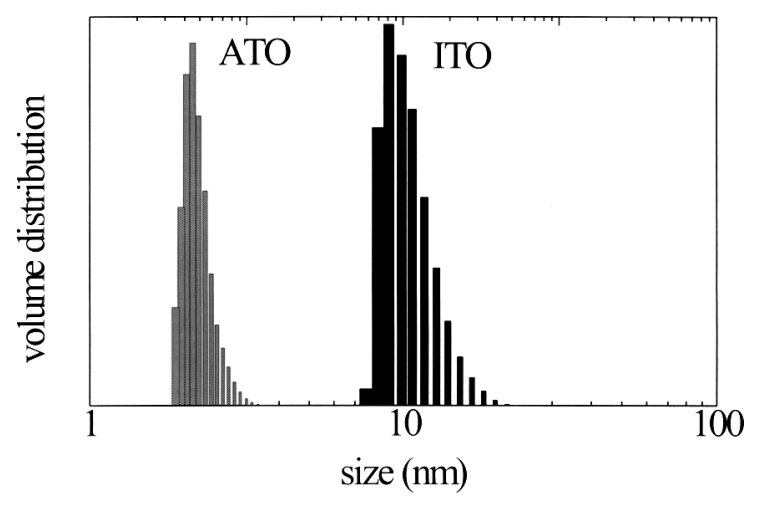

Fig. 5. ATO and ITO hydrodynamic particle size distribution in the suspension.

fully dispersed down to the primary particle size and that each particle appears to be formed by a single crystallite.

The size of the particles was also confirmed by HRTEM (Figs. 6 and 7) with no evidence of aggregation. The aggregates seen in Fig. 7 for the ITO powder are due to the preparation method of the sample for the TEM experiment.

\subsection{Film characterisation}

The film thickness of ATO and ITO increases with the solid content in the dispersion. With solid content higher than 7 Vol.\% (ATO) and 5 Vol.\% (ITO) the coatings are too thick and cracks are observed. A dispersion of ATO particles with a solid content of $5.6 \mathrm{Vol} . \%$ leads to a single film thickness of $200 \mathrm{~nm}$. A $400 \mathrm{~nm}$ thick single layer can be obtained with an ITO suspension of $21 \mathrm{wt} . \%$ solid content. Both coatings have no visible cracks. The resistivity and the

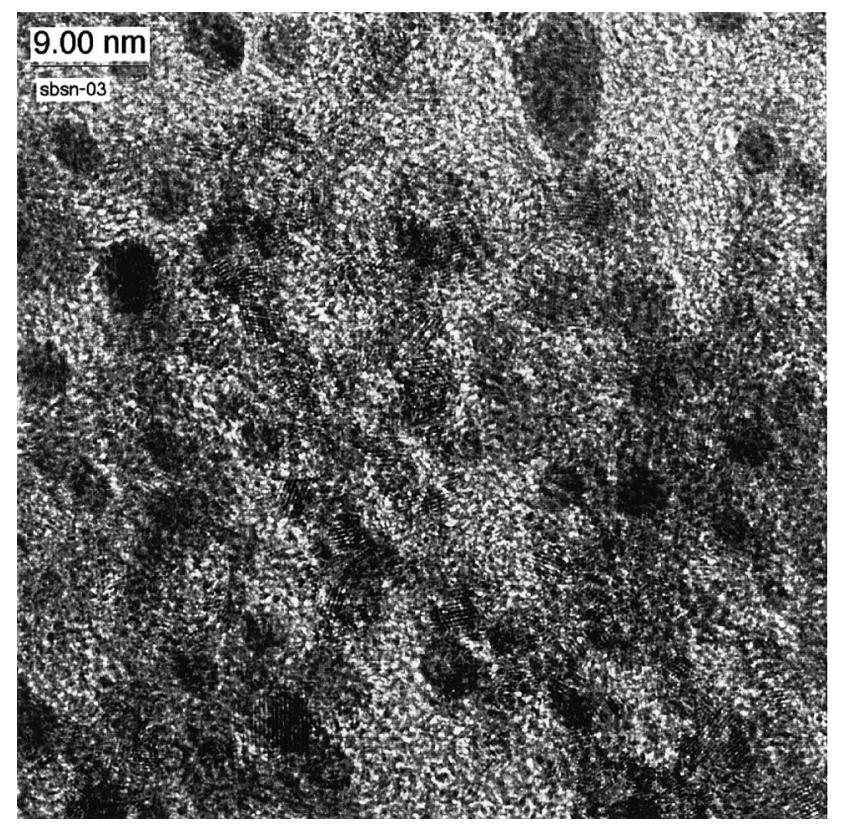

Fig. 6. HRTEM picture of crystalline $\mathrm{SnO}_{2}: \mathrm{Sb}$ nanopowder redispersed in water with TMAH as dispersion agent $(\mathrm{pH}=10)$. 


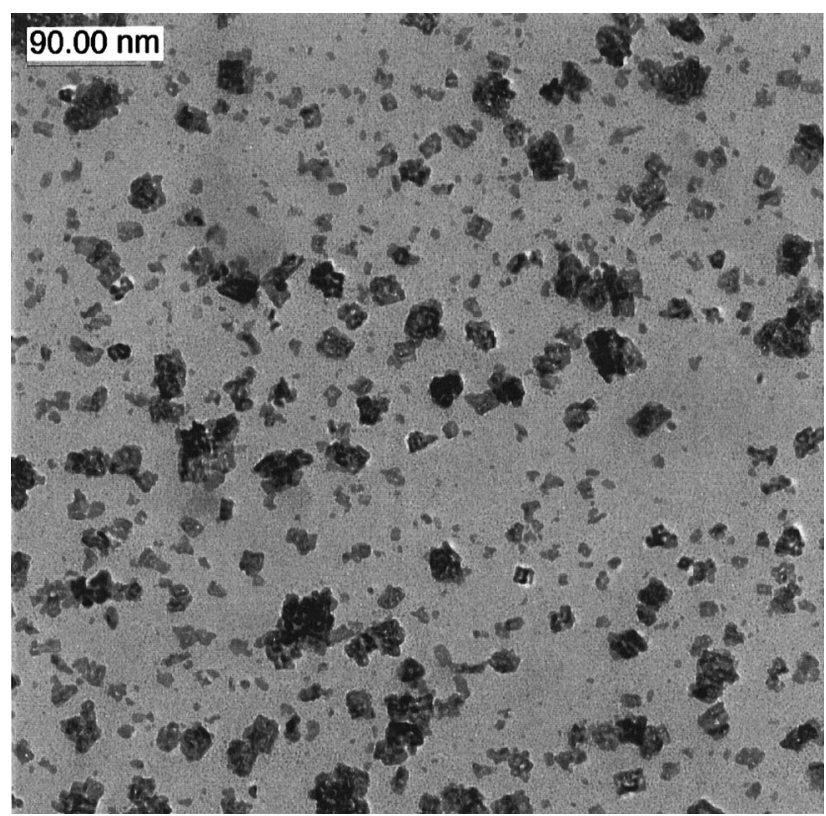

Fig. 7. HRTEM picture of crystalline $\mathrm{In}_{2} \mathrm{O}_{3}:$ Sn nanopowder after annealing and redispersion in ethanol $(\mathrm{pH}=4)$.

sheet resistance of $400 \mathrm{~nm}$ thick ATO (two layers) and ITO (one layer) coatings versus the sintering temperature is shown in Fig. 8 . The values steadily decrease with the increase of the temperature. For ATO coating $\rho$ reaches a minimum of $1.7 \times 10^{-2} \Omega \mathrm{cm}\left(R_{\square}=430 \Omega_{\square}\right)$ at $550^{\circ} \mathrm{C}$. The resistivity of ITO coatings decreases continuously down to $\rho=1.5 \times 10^{-2} \Omega \mathrm{cm}\left(R_{\square}=380 \Omega_{\square}\right)$ at $900^{\circ} \mathrm{C}$. A postannealing of ITO coatings in nitrogen at a temperature of $300^{\circ} \mathrm{C}$ reduces the resistivity and values as small as $\rho=$ $3.4 \times 10^{-3} \Omega \mathrm{cm}\left(R_{\square}=90 \Omega_{\square}\right)$ are obtained for sintering at $900^{\circ} \mathrm{C}$.

A study of the long term stability of ITO films sintered at $550^{\circ} \mathrm{C}$, stored in air at $20^{\circ} \mathrm{C}$ and $40 \%$ relative humidity, is shown in Fig. 9. The sheet resistance of the as sintered coating practically fluctuates around $2 \mathrm{k} \Omega_{\square}$. The sheet resistance of the annealed ITO coating slightly and steadily

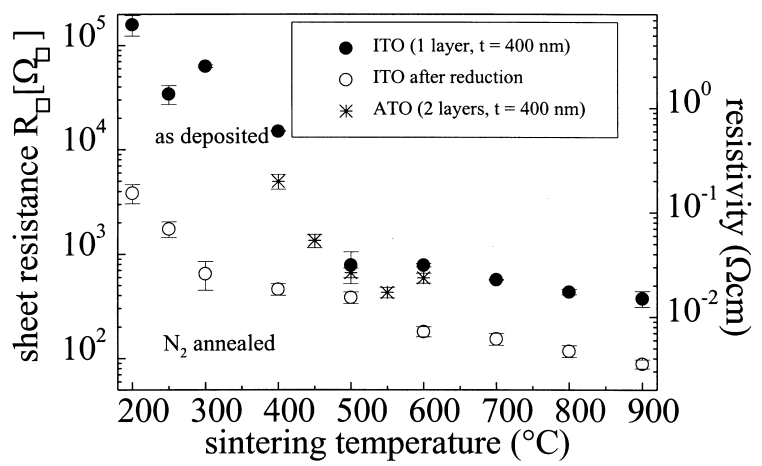

Fig. 8. Sheet resistance (left) and resistivity (right) of $400 \mathrm{~nm}$ thick ATO and ITO coatings versus sintering temperature for a sintering time of 30 min. The ITO coatings were annealed afterwards in a nitrogen atmosphere at $300^{\circ} \mathrm{C}$.

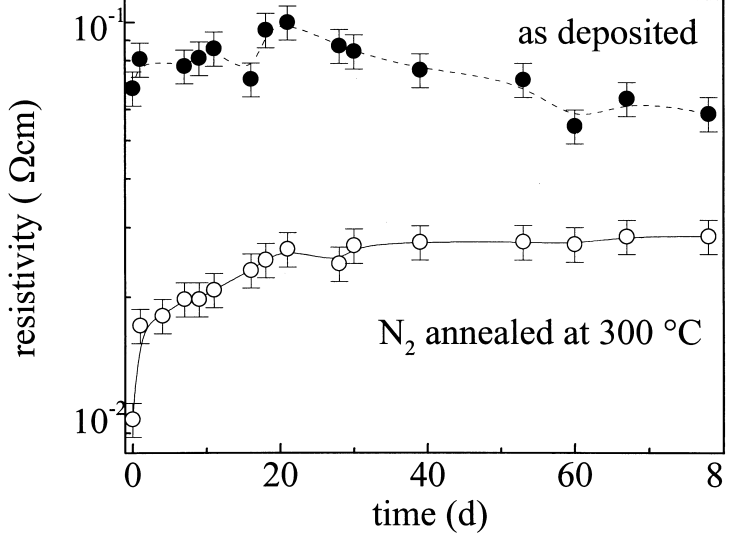

Fig. 9. Time variation of the resistivity of ITO coatings in air $\left(20^{\circ} \mathrm{C}\right.$, $\mathrm{RH}=40 \%)$

increases with time. After 40 days, $\rho$ reaches a value of $2.9 \times 10^{-2} \Omega \mathrm{cm}$ almost three times higher than the value measured immediately after annealing $\left(9.7 \times 10^{3} \Omega \mathrm{cm}\right)$. The reason for the increase in the resistivity of these coatings lays in their high porosity. Oxygen from the surrounding air diffuses into the coatings through the pores and partly eliminates the effect of the annealing.

For most applications a high transmission in the visible range is also important. A typical example of the transmission and reflection properties of $400 \mathrm{~nm}$ thick ATO and ITO coatings in shown in Fig. 10. The transmission in the visible range measured against air is about $90 \%$. This reflects the beneficial effect of using particles in the nanometer range for coating production as these particles practically do not scatter the visible light. The annealed ITO and ATO coatings show a similar increase of the reflectance in the IR range due to the conducting properties of the materials. However, the deposited ITO film has a lower reflectance due to the lower density of the electrons.

Gasparro et al. found that different deposition and heating conditions have a strong influence on the morphology of the coatings [10]. Each layer of single and multilayer coatings

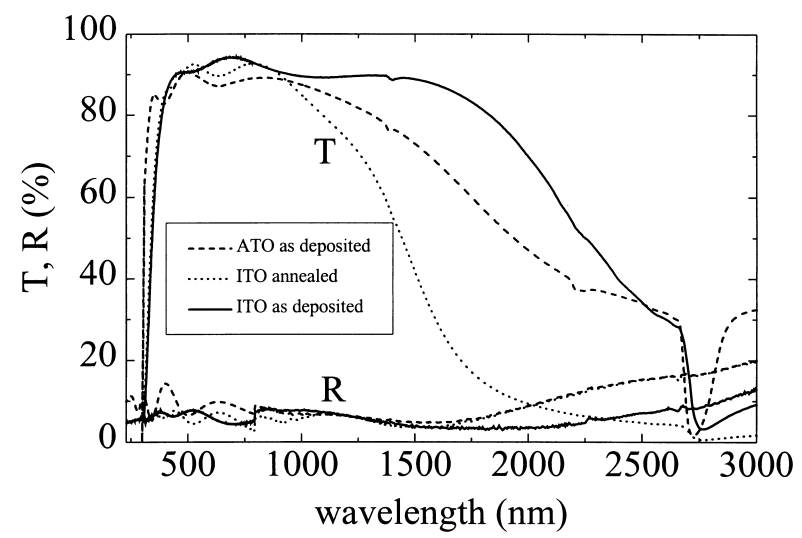

Fig. 10. Reflectance and transmission spectrum of $400 \mathrm{~nm}$ thick ATO and ITO coatings sintered at $550^{\circ} \mathrm{C}$ for $30 \mathrm{~min}$. $\left(R_{\square}(\mathrm{ATO})=430 \Omega_{\square}, R_{\square}\right.$ $($ ITO $)=1 \mathrm{k} \Omega_{\square}, R_{\square}($ ITO annealed $\left.)=250 \Omega_{\square}\right)$ 


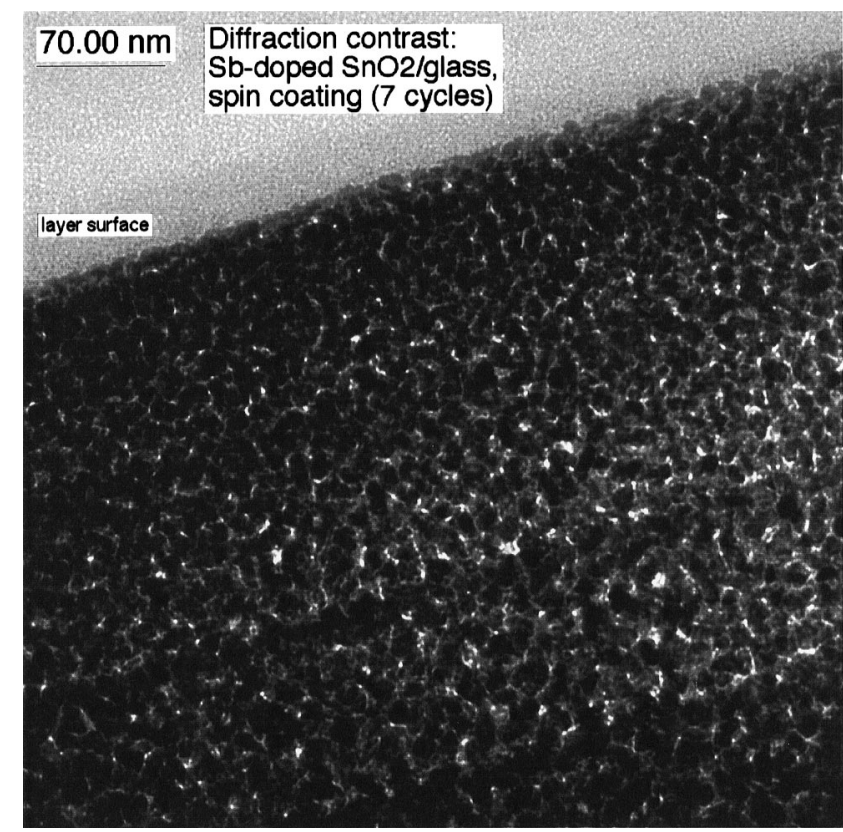

Fig. 11. Cross-section of a multilayer $\mathrm{SnO}_{2}: \mathrm{Sb}$ coating deposited by spin coating on a glass substrate with a particulate sol having a solid content of 7.7 Vol.\%. Each layer was sintered in air at $550^{\circ} \mathrm{C}$ during $15 \mathrm{~min}$.

obtained with sols containing crystalline nanoparticles presents a thin $(<10 \mathrm{~nm})$ dense interface (external part) lying on top of a more porous material (internal part). The layers are composed of small crystallites (Fig. 11). For ATO coatings the surface of the layer is very smooth compared to the ATO and ITO coatings made by sol-gel or sputtering technique (Table 1). This is due to the very small particles (4 $\mathrm{nm}$ ) used to obtain the coatings.

The morphology of the coatings has an influence on the porosity and on the electrical parameters of the coatings. Sintered ATO powders [11] have a total porosity of $63 \%$ practically independent of the sintering temperature. The pore size distribution is narrow and the average value of the pore diameter shifts from $4 \mathrm{~nm}\left(400^{\circ} \mathrm{C}\right)$ to $20 \mathrm{~nm}$ $\left(800^{\circ} \mathrm{C}\right)$ for increasing sintering temperature. The porosity of ATO coatings measured at different temperatures by surface acoustic wave measurements (SAW) shows the same behaviour (Fig. 12). Due to the high porosity the electrons are scattered at the grain boundaries of the particles, leading to a low mobility and a high resistivity. The particulate nature of the ATO and ITO layers explains why the resistivity is still a factor 10 (for ITO) and 100 (for ATO) higher than coatings prepared by physical techniques.

Table 1

Roughness $\mathrm{R}_{\mathrm{a}}(\mathrm{nm})$ measured by SFM of ITO and ATO coatings obtained by different techniques

\begin{tabular}{lll}
\hline Coating technique & ITO & ATO \\
\hline Sputtering & $2.00 \pm 0.02$ & - \\
Sol-gel & - & $2.90 \pm 0.02$ \\
Nanoparticles & $4.60 \pm 0.02$ & $0.40 \pm 0.03$ \\
\hline
\end{tabular}

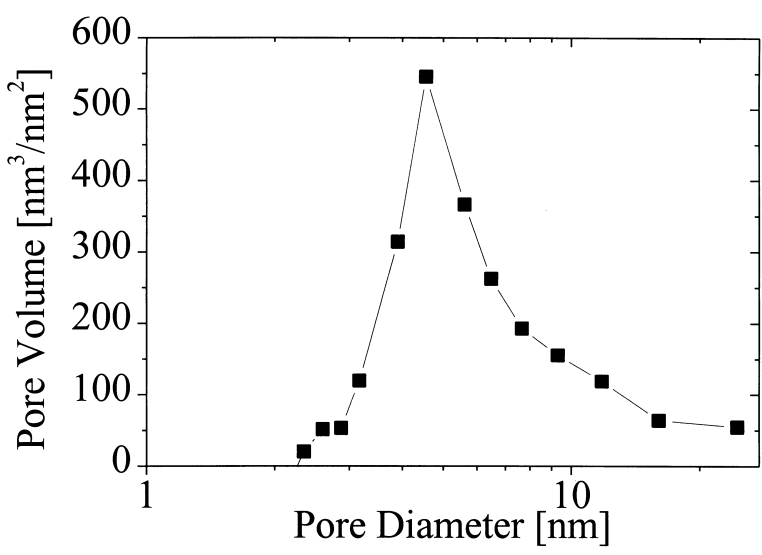

Fig. 12. Pore size distribution of an ATO coating on silica sintered at $400^{\circ} \mathrm{C}$ measured by surface acoustic wave.

\section{Conclusion}

Crystalline $\mathrm{SnO}_{2}, \mathrm{SnO}_{2}: \mathrm{Sb}$ and $\mathrm{In}_{2} \mathrm{O}_{3}: \mathrm{Sn}$ nanoparticles, fully redispersable in water or ethanol have been prepared. The growth of the particles was controlled in an aqueous ammonia solution by chemical modification of the particle surface. The obtained suspension are stable at $\mathrm{pH}>8$ for ATO and $\mathrm{pH}<6$ for ITO. Transparent conducting coatings with thickness up to $500 \mathrm{~nm}$ /layer have been obtained by spin coating (ATO, ITO) and dip coating (ITO) process. The resistivity of $\mathrm{SnO}_{2}: \mathrm{Sb}$ and $\mathrm{In}_{2} \mathrm{O}_{3}: \mathrm{Sn}$ coatings depends on the sintering temperature and annealing processes. For ATO the lowest value of $\rho=1.7 \times 10^{-2} \Omega \mathrm{cm}$ was obtained at a sintering temperature of $550^{\circ} \mathrm{C}$ while for ITO layers the lowest resistivity $\rho=2 \times 10^{-2} \Omega \mathrm{cm}$ was obtained after sintering at $900^{\circ} \mathrm{C}$. This value was reduced to $\rho=$ $3.4 \times 10^{-3} \Omega \mathrm{cm}$ after annealing at $300^{\circ} \mathrm{C}$ in nitrogen atmosphere. The resistivity and consequently the sheet resistance are still a factor 100 (ATO) and 10 (ITO) higher than those obtained by sputtering, CVD or spray pyrolysis processes [12] but the optical transmission of the coatings in the visible range is better $(>90 \%)$.

Nevertheless the use of crystalline ATO and ITO nanopowders offers a new way to produce large transparent conducting coatings for antistatic application or for devices requiring sheet resistance larger than about $300 \Omega_{\square}$ such as touch screen panels. The nanoscaled porosity of these materials which limits the electrical characteristics turn them interesting for the preparation of thick conducting membranes for ultrafiltration [11].

\section{Acknowledgements}

This work was financed by the BMBF (2A67/03N9040) and the State of Saarland (Germany). The authors are grateful to Dr. T. Krajewski for the preparation of the HRTEM images. 


\section{References}

[1] H.L. Hartnagel, A.L. Dawar, A.K. Jain, C. Jagdish, Semiconducting Transparent Thin Films, IOP Publishing, Bristol and Philadelphia, 1995.

[2] R.B.H. Tahar, T. Ban, Y. Ohya, Y. Takahashi, J. Appl. Phys. 83 (1998) 2631.

[3] K.L. Chopra, S. Major, D.K. Pandya, Thin Solid Films 102 (1983) 146.

[4] C. Terrier, J.P. Chatelon, R. Berjoan, J.A. Roger, Thin Solid Films 263 (1995) 37-41.

[5] W. Lada, A. Deptula, T. Olczak, W. Torbicz, D. Pijanowska, J. SolGel Sci. Technol 2 (1994) 551.

[6] G. Gasparro, J. Puetz, D. Ganz, M.A. Aegerter, Solar Energy Mater. Solar Cells 54 (1998) 287.
[7] D. Burgard, C. Kropf, R. Nass, H. Schmidt, Better Ceramics through Chemistry, in: A.K. Cheethan, C.J. Brinker, M.L. Mecartney, C. Sanchez (Eds.), Mater. Res. Soc. Proc., Vol. 346, 1994, pp. 101-107.

[8] D. Burgard, R. Nass, H. Schmidt, Aqueous Chemistry and Geochemistry of Oxides, Oxyhydroxides and Related Materials Vol. 432, MRS, Pittsburgh, PA, 1997, pp. 113-120.

[9] D. Burgard, R. Nass, H. Schmidt, Werkstoffwoche, Symp. 6 Werkstoff und Verfahrenstechnik, DGM Informationsgesellschaft $\mathrm{mbH}$, 1997, pp. 569-577.

[10] G. Gasparro, D. Ganz, C. Goebbert, J. Puetz, M.A. Aegerter, SPIE, in: J.D. Mackenzie (Ed.), Sol-Gel Optics IV, Vol. 3136, 1997.

[11] C. Goebbert, M.A. Aegerter, Detlef Burgard, Ruediger Nass, H. Schmidt, J. Mater. Chem. 9 (1999) 253-258.

[12] H. Bisht, A. Mehrtens, M.A. Aegerter, DGG, 72, Glastechnische Tagung, 1998, p. 235. 